\title{
Downstream balloon dilation technique for endoscopic removal of an impacted pancreatic duct stone after pancreatoduodenectomy
}

Endoscopic retrograde pancreatography is an established modality for the treatment of pancreatic duct stones [1,2]. Although it is technically challenging in patients with prior pancreatoduodenectomy [3,4], balloon-assisted endoscopic retrograde pancreatography and/or endoscopic ultrasound-guided pancreatic

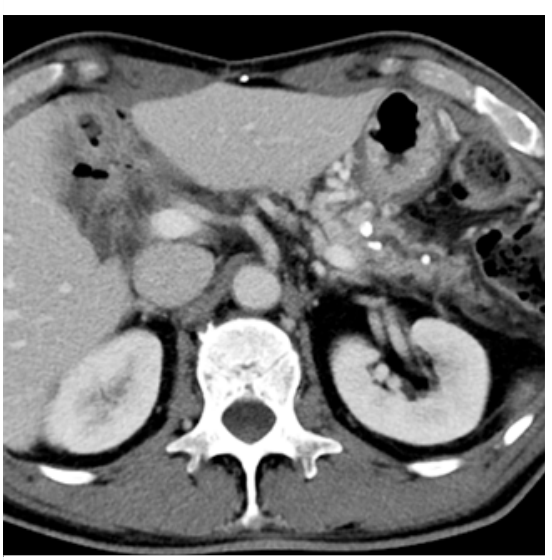

- Fig. 1 Contrast-enhanced computed tomography showed three radiopaque stones in the main duct; one of the three stones was impacted in the main pancreatic duct, resulting in obstructive pancreatitis. drainage has been increasingly utilized to manage pancreatic diseases in patients with surgically altered anatomy [5]. Here we report a simple and feasible technique for the endoscopic removal of an impacted pancreatic duct stone after pancreatoduodenectomy using a short-type singleballoon enteroscope.

A 61-year-old man, who underwent pylorus-preserving pancreatoduodenectomy with modified Child's reconstruction three years earlier for pancreatic neuroendocrine tumor, was referred to our department for the treatment of acute pancreatitis. Contrast-enhanced computed tomography showed three radiopaque stones in the main duct; one of the three stones was impacted in the main pancreatic duct, resulting in obstructive pancreatitis ( $\mathbf{F i g} \mathbf{1}$ ). Therefore, an endoscopic intervention was performed using a short-type single-balloon enteroscope (SIF-H290S; Olympus Medical Systems, Tokyo, Japan) with a transparent hood. A tapered double-lumen catheter with a tip diameter of $3.6 \mathrm{Fr}$ (Uneven Double Lumen Cannula Standard Type; Piolax Medical Devices, Kanagawa, Japan) was advanced through the pancreaticojejunal anastomosis, and a 0.025-inch guidewire (VisiGlide 2; Olympus Medical Systems) was placed into the pancreatic duct; however, the catheter could not pass through the impacted stone at all. After placing an additional guidewire, the section downstream of the stone was dilated with a $6-\mathrm{mm}$ balloon catheter (REN; Kaneka Medix, Osaka, Japan) ( Fig.2a), and as the balloon deflated, the impacted stone moved downstream toward the balloon (-Fig. 2b, > Video 1).

Finally, the pancreatic stones were successfully retrieved by using a wire-guided basket catheter (TetraCatch V; Olympus Medical Systems) ( Fig. 2 c, \ Fig.3).

The downstream balloon dilation technique is simple and is worth a try when confronting impacted pancreatic duct stones.

Endoscopy_UCTN_Code_TTT_1AR_2AH

\section{Competing interests}

The authors declare that they have no conflict of interest.
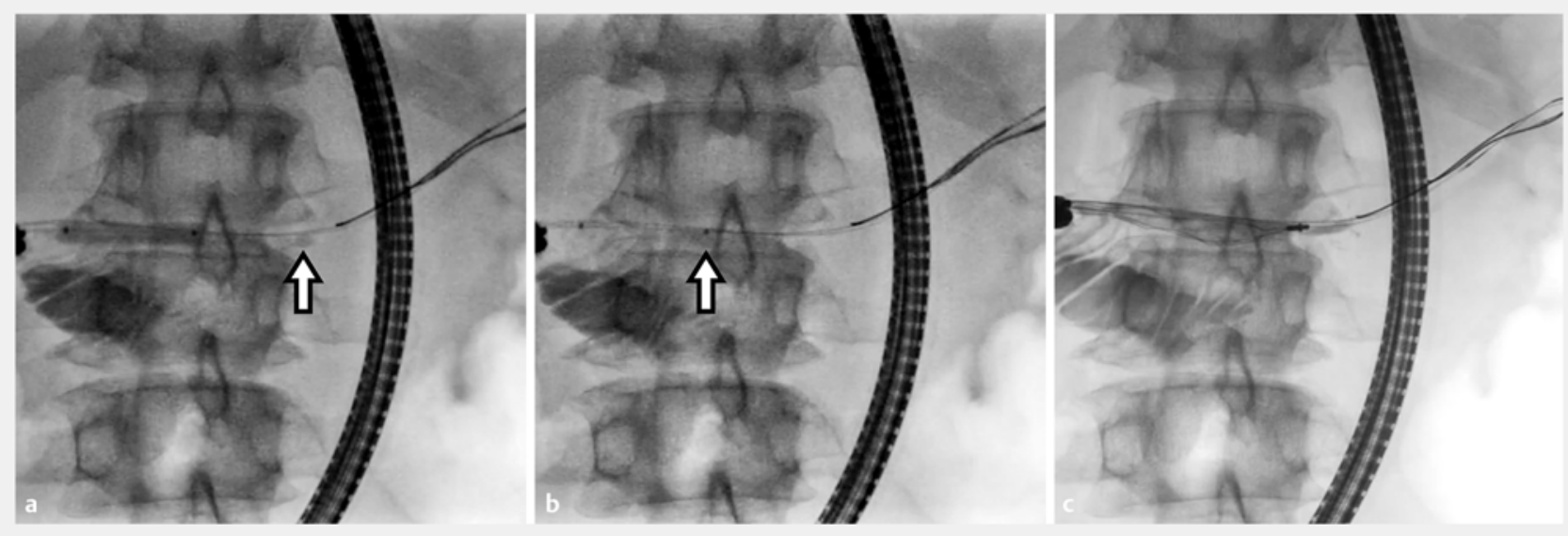

- Fig. 2 Fluoroscopic images. a An impacted pancreatic duct stone (arrow) during the downstream balloon dilation. b As the balloon deflated, the pancreatic duct stone (arrow) moved downstream toward the balloon. $\mathbf{c}$ The pancreatic stone was captured with a wire-guided basket catheter. 


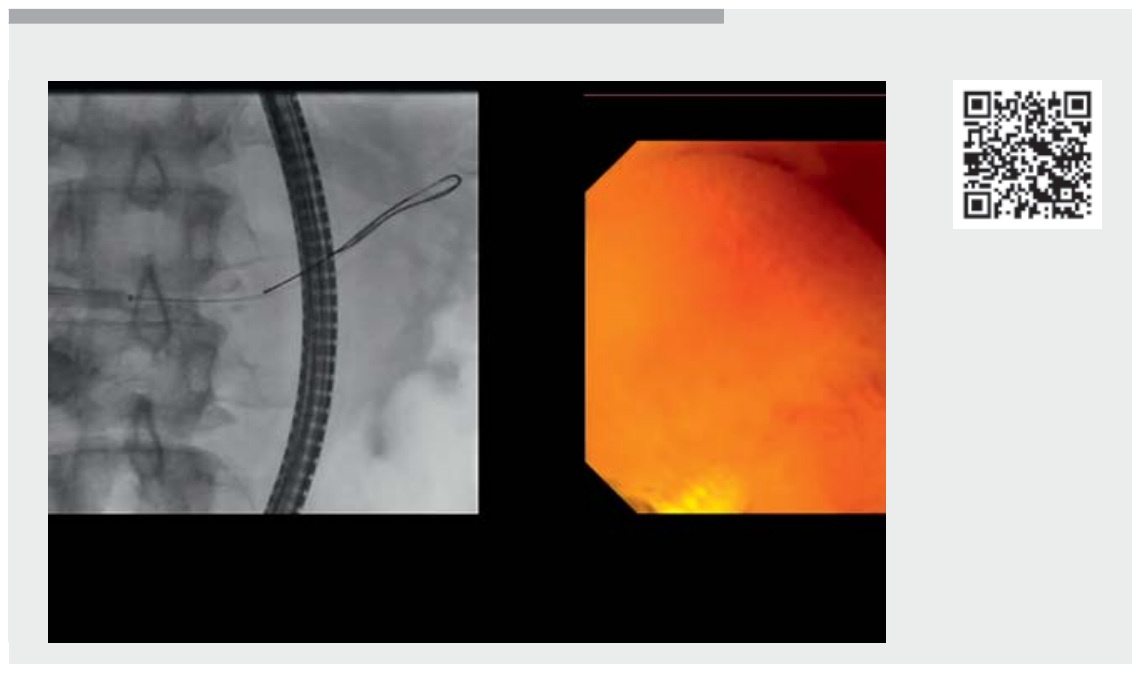

$\checkmark$ Video 1 Downstream balloon dilation technique for endoscopic removal of an impacted pancreatic duct stone after pancreatoduodenectomy.

The authors

\section{Sho Kitagawa $\$, Shori Ishikawa, Keiya Okamura}

Department of Gastroenterology, Sapporo Kosei General Hospital, Sapporo, Japan

\section{Corresponding author}

\section{Sho Kitagawa, MD}

Department of Gastroenterology, Sapporo Kosei General Hospital, Kita 3 Higashi 8, Chuo-ku, Sapporo 060-0033, Japan

Fax: +81112715320

bossa0405@yahoo.co.jp

\section{References}

[1] Dumonceau JM, Delhaye M, Tringali A et al. Endoscopic treatment of chronic pancreatitis: European Society of Gastrointestinal Endoscopy (ESGE) Guideline - Updated August 2018. Endoscopy 2019; 51: 179-193
[2] Kitano M, Gress TM, Garg PK et al. International consensus guidelines on interventional endoscopy in chronic pancreatitis. Recommendations from the working group for the international consensus guidelines for chronic pancreatitis in collaboration with the International Association of Pancreatology, the American Pancreatic Association, the Japan Pancreas Society, and European Pancreatic Club. Pancreatology 2020; 20: 1045-1055

[3] Chahal P, Baron TH, Topazian MD et al. Endoscopic retrograde cholangiopancreatography in post-Whipple patients. Endoscopy 2006; 38: 1241-1245

[4] Farrell ], Carr-Locke D, Garrido T et al. Endoscopic retrograde cholangiopancreatography after pancreaticoduodenectomy for benign and malignant disease: indications and technical outcomes. Endoscopy 2006; 38: 1246-1249

[5] Kogure H, Sato T, Nakai Y et al. Endoscopic management of pancreatic diseases in patients with surgically altered anatomy: clinical outcomes of combination of double-balloon endoscopy- and endoscopic ultrasound-guided interventions. Dig Endosc 2021; 33: 441-450

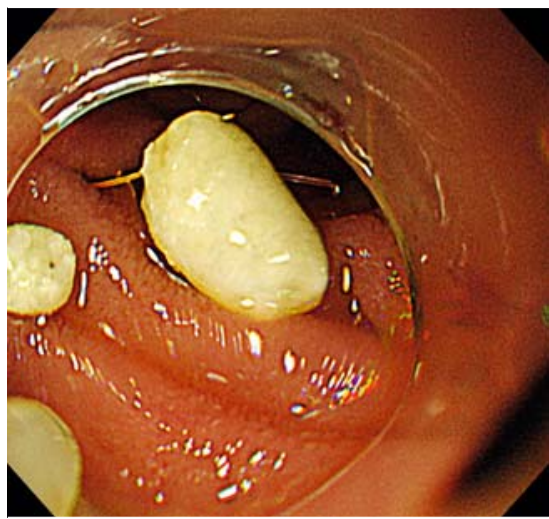

-Fig. 3 Endoscopic view of pancreatic duct stones retrieved from the main pancreatic duct.

Bibliography

Endoscopy 2022; 54: E506-E507

DOI 10.1055/a-1645-1335

ISSN 0013-726X

published online 15.10.2021

(c) 2021. Thieme. All rights reserved.

Georg Thieme Verlag KG, Rüdigerstraße 14, 70469 Stuttgart, Germany

\section{ENDOSCOPY E-VIDEOS}

https://eref.thieme.de/e-videos

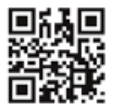

Endoscopy E-Videos is an open access online section, reporting on interesting cases and new techniques in gastroenterological endoscopy. All papers include a high quality video and all contributions are freely accessible online. Processing charges apply (currently EUR 375), discounts and wavers acc. to HINARI are available.

This section has its own submission website at https://mc.manuscriptcentral.com/e-videos 